DOI 10. 18307/2016. 0606

(C) 2016 by Journal of Lake Sciences

\title{
1990 年以来北京密云水库主要水环境因子时空分布特征”
}

\author{
曾庆慧 ${ }^{1,2}$, 秦丽欢 ${ }^{1,2}$, 程 鹏 $^{1,2}$, 李叙勇 ${ }^{1 *^{*}}$, 贾东民 ${ }^{3}$, 潘轫旻 ${ }^{3}$ \\ (1:中国科学院生态环境研究中心城市与区域生态国家重点实验室,北京 100085) \\ (2: 中国科学院大学,北京 100049) \\ (3: 北京市密云水库管理处, 北京 101512)
}

\begin{abstract}
摘 要: 根据 1990-2011 年密云水库共 12 个监测点的月监测资料,采用聚类分析研究各监测点水环境相似性及空间分 布特征, 采用因子分析识别影响水质的主要因子并评价各采样点的综合水质. 通过绝对主成分多元回归分析, 获得汛期 和非汛期各因子对各水质指标的贡献率. 利用季节性 Kendall 检验及流量调节检验对密云水库库区水化学特征和水质状 况时空分布特征进行了研究. 结果表明: 汗期水质主要受到农业营养物质的影响, 其次为生物化学因素和有机物的影响. 非汛期水质主要受到农牧业排放因素的影响, 其次为人类活动和生物化学因素的影响. 因子得分综合评价显示, 汛期辛 庄桥、内湖和大关桥综合水质较差, 潮河、库西和白河综合水质较好. 非汛期辛庄桥、石佛桥和大关桥综合水质较差, 库 东、套里和恒河综合水质较好. 主要水质指标的年际变化规律不同, 但最终都趋于平稳. 与潮河、白河人库水质变化相比, 库区水质变化趋势较小, 上游人库水质和库区水质都整体趋好. 除白河人库的总氮和总磷外,其他监测指标的变化趋势 经流量调节前后基本一致,表明流量并不是引起水质趋势变化的主要因素,水质的变化主要是由于污染源变化而引起.

关键词: 密云水库; 聚类分析; 因子分析; 绝对主成分多元回归分析;季节性 Kendall 分析
\end{abstract}

\section{Spatial and temporal distribution of main aquatic environment factors in Miyun Reservoir, Beijing since 1990s}

\author{
ZENG Qinghui ${ }^{1,2}$, QIN Lihuan ${ }^{1,2}$, CHENG Peng ${ }^{1,2}$, LI Xuyong ${ }^{1 * *}$, JIA Dongmin ${ }^{3} \&$ PAN Kemin ${ }^{3}$ \\ (1: State Key Laboratory of Urban and Regional Ecology, Research Center for Eco-Environmental Sciences, Chinese Academy \\ of Sciences, Beijing 100085, P.R. China) \\ (2: University of Chinese Academy of Sciences, Beijing 100049, P.R.China) \\ (3: Miyun Reservoir Administration of Beijing, Beijing 101512,P.R.China)
}

Abstract: Monthly monitoring data of totally 12 monitoring sites in Miyun Reservoir from 1990 to 2011 were collected. Cluster anal-
ysis was used to analyze the spatial distribution of hydrogeochemical characteristics of these sites. Factor analysis was used to identi-
fy the main factors affecting water quality and evaluate the comprehensive water quality of each monitoring site. The multivariate lin-
ear regression of the absolute principal component scores (APCS-MLR) was employed to quantify the contribution rate of each fac-
tor on water quality indicators in both flood and non-flood seasons. The results indicated that: water quality was mainly affected by
agricultural nutrients, biochemical factor and organics in flood season. While in non-flood season it was mainly affected by farming
and husbandry emissions, human activities and biochemical factors. Factor score evaluation showed that the comprehensive water
quality of Xinzhuangqiao, Neihu and Kudong were worse and that of Chaohe, Kuxi and Baihe were better in flood season. In non-
flood season, the comprehensive water quality of Xinzhuangqiao, Shifoqiao and Daguanqiao were worse and that of Kudong, Taoli
and Henghe were better. The interannual trends of main water quality pollutants were different, but all leveled off eventually. Water
quality changed less in the reservoir compared with water quality coming from Chaohe and Baihe. Water quality of both reservoir
and watershed was getting better. Changing trend of water quality indicators were basically the same before and after flow control test
except for TN and TP in Baihe. It indicated that the main factor causing water quality changes was not flow but pollution source

* 国家水体污染控制与治理科技重大专项(2014ZX07203010-1) 资助. 2015-11-06 收稿;2016-03-16 收修改稿. 曾 庆慧( 1990 ) ,女,博士研究生;E-mail:qhzeng1990@126.com.

** 通信作者; E-mail:xyli@ rcees.ac.cn. 
changes.

Keywords: Miyun Reservoir; cluster analysis; factor analysis; APCS-MLR; seasonal Kendall analysis

密云水库 $\left(40^{\circ} 30^{\prime} \mathrm{N}, 116^{\circ} 56^{\prime} \mathrm{E}\right)$ 是北京市城市生活用水的主要地表水源, 位于北京市中心东北约 $100 \mathrm{~km}$ 的密云县, 是一个山谷型的半封闭型的水库, 它是潮白河水系上最大的水库, 全库最大蓄水量 $43.75 \times 10^{8} \mathrm{~m}^{3}$, 相应水面面积 $188 \mathrm{~km}^{2}$, 最大水深 $43.5 \mathrm{~m}^{[1-3]}$. 近年密云水库开展了多项水华防治工作, 但由于水库蓄水量的 大幅减少, 水质已面临富营养化的威胁, 水库部分区域已出现富营养化的征兆 ${ }^{[4-5]}$. 充足的营养物质是发生 富营养化的必要条件, 因此, 对密云水库的水质状况进行评价分析, 对于控制水体富营养化、为库区水资源 保护提供科学依据有十分重要的意义.

目前, 我国已开展了大量的水质监测工作, 然而由于水体中的物理化学过程复杂, 使水环境问题诊断和 识别非常困难 ${ }^{[6]}$. 将主成分分析、因子分析等多元统计方法应用于河流、湖泊、地下水等环境领域, 可以更好 地说明水质的时空变化规律, 在国内外的水质评价与分析中已得到广泛的应用 ${ }^{[7-8]}$. 密云水库水环境质量已 经引起国内外学者的广泛关注, 相继开展了密云水库水体的地球化学特征 ${ }^{[9]}$ 、密云水库东西库区的水质与 浮游藻类分析 ${ }^{[10]}$ 、密云水库总磷的富营养化分析与预测 ${ }^{[11]}$ 、密云水库中氮分布及迁移影响因素研究 ${ }^{[12]}$ 等 研究. 但是利用多元统计方法, 对密云水库近 22 年的水质变化进行系统、详细的评价研究还不多见.

本文运用多元统计方法中的聚类分析对 1990-2011 年密云水库库区内共 12 个监测点 (图 1,1 大关桥、 2 辛庄桥、 3 内湖、 4 石佛桥、 5 白河、6 库西、7 库东、8 套里、9 恒河、10 潮河、11 水源九厂、12 金沟) 进行聚类 研究, 分析密云水库库区监测点的水质现状、各监测点水环境相似性及空间分布特征. 运用因子分析和绝对 主成分多元回归分析法识别影响水质的主要因子及各因子对水质指标的贡献率. 此外,由于水质检测指标 的浓度受水量多少的直接影响, 而不同季节的河流径流量存在着季节性周期变化, 因此不同季节的水质资 料缺乏直接可比性 ${ }^{[13]}$, 本文选取属非参数检验方法的季节性 Kendall 检验及流量调节检验法分析历年相同 月份的水质资料, 研究了各水质指标的时间分布特征. 旨在客观评估密云水库库区水质现状, 为日后有效的 进行水资源管理和改善治理提供科学依据.

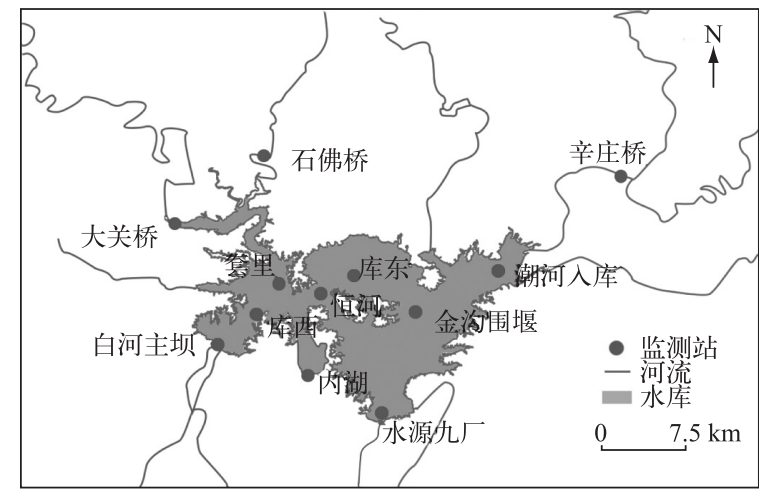

图 1 密云水库监测点位示意

Fig.1 Water quality monitoring sites in Miyun Reservoir

\section{1 数据来源与分析方法}

\section{1 数据来源}

本研究所用数据集合为 1990-2011 年密云水库库区内共 12 个监测点的月监测数据, 每个监测点监测 9 个水质参数,包括: $\mathrm{pH}$ 、电导率、浊度、氯化物、高锰酸盐指数、五日生化需氧量、氨氮、硝酸盐氮、总氮. 所有 监测点所采用的水质数据均来源于密云水库管理处, 采样和测试均符合国家水文水质监测标准.采用 SPSS 19 软件及美国地质调查局 (USGS) 开发的季节性 Kendall 检验程序进行分析. 


\section{2 数据分析与处理}

1.2.1 聚类分析 考虑到不同水质指标之间存在数量级和单位的差异, 首先对数据进行标准化. 利用 SPSS 19 软件对 1990-2011 年库区内 12 个监测点 (图 1) 进行聚类分析. 方法为系统聚类法, 选择组间联接的聚 类方法,亲疏程度的计算选用平方 Euclidean 距离作为度量标准,使水质特征相似的监测点聚成一类.

1.2.2 因子分析 本文将水质数据按汛期和非汛期分类后进行因子分析, 因子载荷矩阵采用主成分分析法提 取特征值, 采用特征值是否大于 1 作为判别依据, 提取主成分. 为了使因子的含义更加清晰使之更具有命名 解释性, 采用方差最大法对因子载荷矩阵实行正交旋转 ${ }^{[14]}$, 按第一因子降序的顺序输出旋转后的因子载荷, 分别提取出汛期和非汛期对水质有主要影响的因子. 根据因子得分系数矩阵可以分别得出每个因子的得分 函数, 并由因子得分函数计算出每个监测点各因子得分. 再根据每个因子的方差贡献率和各监测点的因子 得分可计算出监测点的因子综合得分, 详细计算方法参见文献 ${ }^{[15-16]}$.

1.2.3 绝对主成分多元回归分析 (APCS-MLR) APCS-MLR 是一种基于因子得分,评价各个因子对各个变量 贡献的统计方法 ${ }^{[17]}$. 其原理是以绝对因子得分为自变量, 污染物浓度为因变量进行多元线性回归. 回归方 程的系数可以将因子得分换算为各个污染源的污染物质量贡献浓度 ${ }^{[18-20]}$. APCS-MLR 可用于量化河流水体 的污染源贡献率,进而推导每个识别的主因子的来源及贡献率 ${ }^{[21-24]}$, 具体公式参见已有研究 ${ }^{[21,25]}$. 本文采用 绝对主成分多元线性回归分析法确定各影响因子对各水质指标的贡献率,量化分析污染源对不同水质指标 的影响程度.

1.2.4 季节性 Kendall 检验及流量调节检验 季节性 Kendall 检验将历年相同月份的水质资料进行比较, 只考 虑数据相对排列而不考虑其大小, 其主要优点是避免了季节性的影响, 同时不受水质资料的非正态性、季节 性变化、流量相关、出现漏测值或小于检测限值等的影响 ${ }^{[26-27]}$. 检验原理及具体模型详见文献 [26,28]. 根据 模型要求, 水质序列过短无法准确判断是否存在趋势, 而水质序列过长会导致趋势被掩盖或抵消, 检验年数 一般不小于 5 年, 不大于 12 年 ${ }^{[29]}$. 因此, 本文选取 2004-2011 年共 8 年的逐月监测数据进行水质趋势分 析, 分析参数包括总氮、总磷、高锰酸盐指数和五日生化需氧量.

一般情况下, 水质变化还受到降雨、径流、人类活动等多种因素的影响, 为了判断水质变化是由流量因 素造成的还是由污染源变化造成的, 还需进行季节性 Kendall 流量调节检验 ${ }^{[30]}$. 由于库东的流量数据不完 整, 本文只对白河人库和潮河人库 2 个监测点的监测指标进行季节性 Kendall 流量调节检验. 本文季节性 Kendall 检验及流量调节检验采用美国地质调查局( USGS) 开发的季节性 Kendall 检验程序.

\section{2 结果与讨论}

\section{1 水质总体特征}

密云水库 12 个监测点 1990-2011 年间水质参数的相关关系矩阵及水质监测总体特征可以看出,密云 水库库区水质基本满足生活饮用水卫生要求 (表 1). 除浊度外,其他监测指标的变异系数均小于 $100 \%$,说 明监测指标都没有很强时空差异性. 其中 $\mathrm{pH}$ 、电导率、氯化物、高锰酸盐指数、五日生化需氧量的变异系数 小于 $20 \%$, 说明其时空变异性小, 浓度相对稳定. 氨氮、硝酸盐氮和总氮的变异系数介于 $40 \% \sim 100 \%$ 之间, 显 示出中等变异性, 说明浓度具有一定的离散性. 浊度的变异系数大于 $100 \%$, 说明浊度受人为影响很大, 具有 强变异性. 除了总氮以外,其他指标均符合 GB 3838-2002 水质评价标准 II 类标准.

\section{2 水质空间分布特征}

聚类分析的结果见图 2, 以距离 10 为基准, 可将全部监测点分为 3 类,第一类包括: 1 大关桥、 3 内湖、 5 白河、6 库西、7 库东、8 套里、9 恒河、10 潮河、11 水源九厂、12 金沟,第一类水体主要分布于密云水库库区内 部, 水质状况相对较好. 第二类水体为 4 石佛桥, 是密云水库上游白河人库监测点之一. 第三类水体为 2 辛 庄桥, 辛庄桥是密云水库上游潮河人库监测点. 第二类和第三类监测点分别位于白河和潮河人库上游处, 水 质较第一类差. 已有研究表明, 密云水库河流人库处沉积物的总氮、总磷浓度较高, 这可能是由于河流携带 的营养物质在人库处发生沉积 ${ }^{[31]}$, 因此水质较库区内差. 其中, 大关桥是白河人库口, 与库区监测点分为一 类, 这是由于白河流域人类活动和农业集约化程度远低于潮河流域, 潜在非点源污染较潮河流域少 ${ }^{[32]}$. 白 河流域水质明显优于潮河流域,大关桥的各项水质指标更接近库区内部因而分在第一类中. 
表 1 1990-2011 年密云水库水质参数相关系数矩阵及统计描述

Tab.1 Correlations and statistic description of water quality parameters in Miyun Reservoir during 1990 - 2011

\begin{tabular}{|c|c|c|c|c|c|c|c|c|c|c|c|c|c|c|}
\hline \multirow[b]{2}{*}{ 指标 } & \multicolumn{9}{|c|}{ 相关系数矩阵 } & \multicolumn{5}{|c|}{ 描述性统计 } \\
\hline & $\mathrm{pH}$ & $\begin{array}{c}\text { 电导 } \\
\text { 率 }\end{array}$ & 浊度 & $\begin{array}{c}\text { 氯化 } \\
\text { 物 }\end{array}$ & $\begin{array}{c}\text { 高锰 } \\
\text { 酸盐 } \\
\text { 指数 }\end{array}$ & $\begin{array}{c}\text { 五日生 } \\
\text { 化需 } \\
\text { 氧量 }\end{array}$ & 氨氮 & $\begin{array}{l}\text { 硝酸 } \\
\text { 盐氮 }\end{array}$ & 总氮 & $\begin{array}{c}\text { 极小 } \\
\text { 值 }\end{array}$ & $\begin{array}{c}\text { 极大 } \\
\text { 值 }\end{array}$ & 均值 & $\begin{array}{c}\text { 标准 } \\
\text { 差 }\end{array}$ & $\begin{array}{c}\text { 变异 } \\
\text { 系数/ } \\
\%\end{array}$ \\
\hline $\mathrm{pH}$ & 1.00 & -0.41 & -0.32 & 0.27 & 0.34 & -0.77 & 0.01 & -0.62 & -0.62 & 7.97 & 8.34 & 8.14 & 0.12 & 1.44 \\
\hline 电导率/ $(\mu \mathrm{S} / \mathrm{cm})$ & & 1.00 & 0.57 & 0.72 & -0.63 & 0.26 & 0.50 & 0.84 & 0.853 & 308.86 & 453.023 & 348.72 & 49.22 & 14.11 \\
\hline 浊度/( mg/L) & & & 1.00 & 0.55 & -0.33 & 0.59 & 0.80 & 0.81 & 0.83 & 1.71 & 119.21 & 16.79 & 34.742 & 206.93 \\
\hline 氯化物/( mg/L) & & & & 1.00 & -0.32 & -0.15 & 0.69 & 0.51 & 0.53 & 10.28 & 14.23 & 11.80 & 1.47 & 12.49 \\
\hline 高锰酸盐指数 $/(\mathrm{mg} /$ & & & & & 1.00 & -0.01 & 0.04 & -0.59 & -0.53 & 2.37 & 3.82 & 2.73 & 0.38 & 14.07 \\
\hline 五日生化需氧量/ ( $\mathrm{m}$ & $(\mathrm{L})$ & & & & & 1.00 & 0.44 & 0.52 & 0.56 & 0.95 & 1.43 & 1.21 & 0.15 & 12.30 \\
\hline 氨氮/( mg/L) & & & & & & & 1.00 & 0.51 & 0.56 & 0.09 & 0.27 & 0.14 & 0.06 & 40.79 \\
\hline 硝酸盐氮/ $(m g / L)$ & & & & & & & & 1.00 & 1.00 & 0.30 & 3.28 & 0.96 & 0.81 & 84.45 \\
\hline 总氮/( mg/L) & & & & & & & & & 1.00 & 0.78 & 3.86 & 1.35 & 0.88 & 65.22 \\
\hline
\end{tabular}

\section{3 水环境因子空间综合评价}

根据检验结果, 汛期和非汛期的巴特利特 球度检验 (Bartlett test of sphericity) 统计量的相 应概率都为 $0.000<0.05$, KMO ( Kaiser-MeyerOlkin) 值都介于 $0.5 \sim 0.7$ 之间, 表明数据具有一 定的相关性,比较适合做因子分析 ${ }^{[20]}$. 汛期和 非汛期因子载荷矩阵和因子得分系数矩阵分别 见表 2 和表 3.

由旋转后因子载荷可知, 汛期主成分分析 中共提取了 3 个特征值大于 1 的公因子, 累计 贡献率达到 93.93\% (表 2). 因子 1 与氯化物、 电导率、氨氮、总氮、硝酸盐氮、浊度呈正相关, 主要反映了农业营养物质对水体的影响, 这部 分因素的方差贡献率占 $44.61 \%$. 因子 2 与 $\mathrm{pH}$ 呈负相关,与五日生化需氧量呈正相关,方差贡 献率占 $32.75 \%$,主要是水体内生物化学因素的 素对水质的影响, 方差贡献率占 $16.57 \%$. 3 个因子共解释了 $93.93 \%$ 的水质变异, 剩余因子的贡献率仅为 $6.07 \%$.

由旋转后因子载荷可知, 非汛期主成分分析中共提取了 3 个特征值大于 1 的公因子, 累计贡献率达到 $92.52 \%$ (表 3 ). 因子 1 主要与电导率、硝酸盐氮、总氮呈正相关, 与高锰酸盐指数呈负相关, 该主成分主要反 映了农牧业排放引起的污染,这部分因素的方差贡献率占 $37.70 \%$. 因子 2 方差贡献率占 $29.57 \%$,其中氨氮 和浊度占有较高的因子载荷, 主要反映了人类活动所产生的污染. 因子 3 与五日生化需氧量呈正相关, 与 $\mathrm{pH}$ 呈负相关, 方差贡献率占 $25.24 \%$, 主要是水体内生物化学因素的影响 ${ }^{[33]} .3$ 个因子共解释了 $92.52 \%$ 的水 质变异,剩余因子的贡献率仅为 $7.48 \%$.

本文通过 APCS-MLR 进一步计算了汛期和非汛期不同影响因子对各水质指标的贡献率,结果表明汛期 密云水库库区水质主要受到农业营养物质的影响,其次为水体内生物化学因素和有机物的影响. 农业营养 物质主要影响氯化物、电导率、氨氮、总氮和硝酸盐氮, 其贡献率分别为 $91.3 \% 、 85.2 \% 、 84.9 \% 、 71.2 \%$ 和 $66.7 \%$. 生物化学因素主要影响五日生化需氧量、硝酸盐氮、总氮和浊度,其贡献率分别为 $76.3 \% 、 64.1 \%$ 、 $60.3 \%$ 和 $57.2 \%$. 有机物影响因素对高锰酸盐指数的贡献率达到了 $93.4 \%$, 对五日生化需氧量的贡献率为 
56.3\% (表 2). 非汛期密云水库库区水质主要受到农牧业排放因素的影响,其次为人类活动因素和水体生物 化学因素的影响. 农牧业排放因素主要影响电导率、硝酸盐氮和总氮,贡献率分别为 $87.7 \% 、 75.4 \%$ 和 $70.6 \%$. 人类活动主要影响氨氮和浊度, 贡献率分别为 $91.8 \%$ 和 $84.4 \%$. 生物化学因素主要影响五日生化需氧量、总 氮和硝酸盐氮,贡献率分别为 $88.4 \% 、 52.7 \%$ 和 $48.6 \%$ (表 3 ).

表 2 1990-2011 年汛期旋转后因子载荷、因子得分系数矩阵及污染源贡献率

Tab.2 Rotated component matrix, component score matrix and contribution of pollutant sources in flood season during $1990-2011$

\begin{tabular}{|c|c|c|c|c|c|c|c|c|c|}
\hline \multirow{2}{*}{ 指标 } & \multicolumn{3}{|c|}{ 旋转后因子载荷 } & \multicolumn{3}{|c|}{ 因子得分系数矩阵 } & \multicolumn{3}{|c|}{ 污染贡献率/\% } \\
\hline & 因子 1 & 因子 2 & 因子 3 & 因子 1 & 因子 2 & 因子 3 & 因子 1 & 因子 2 & 因子 3 \\
\hline 氯化物 & 0.95 & -0.24 & -0.16 & 0.35 & -0.28 & 0.03 & 91.3 & & \\
\hline 电导率 & 0.89 & 0.19 & -0.18 & 0.24 & -0.06 & -0.06 & 85.2 & 18.4 & \\
\hline 氨氮 & 0.89 & 0.27 & 0.25 & 0.28 & -0.09 & 0.25 & 84.9 & 25.5 & 24.3 \\
\hline 总氮 & 0.74 & 0.63 & -0.14 & 0.11 & 0.17 & -0.11 & 71.2 & 60.3 & \\
\hline 硝酸盐氮 & 0.70 & 0.67 & -0.18 & 0.08 & 0.20 & -0.15 & 66.7 & 64.1 & \\
\hline 浊度 & 0.69 & 0.60 & 0.12 & 0.13 & 0.12 & 0.08 & 66.1 & 57.2 & 11.0 \\
\hline $\mathrm{pH}$ & -0.09 & -0.97 & 0.04 & 0.17 & -0.44 & 0.16 & & & 38.0 \\
\hline 五日生化需氧量 & 0.02 & 0.80 & 0.59 & -0.08 & 0.28 & 0.31 & 1.8 & 76.3 & 56.3 \\
\hline 高锰酸盐指数 & -0.08 & -0.02 & 0.98 & 0.09 & -0.14 & 0.70 & & & 93.4 \\
\hline 特征值 & 4.01 & 2.95 & 1.49 & & & & & & \\
\hline 方差贡献率 & $44.61 \%$ & $32.75 \%$ & $16.57 \%$ & & & & & & \\
\hline 累计贡献率 & $44.61 \%$ & $77.36 \%$ & $93.93 \%$ & & & & & & \\
\hline
\end{tabular}

表 3 1990-2011 年非汛期旋转后因子载荷、因子得分系数矩阵及污染源贡献率

Tab.3 Rotated component matrix, component score matrix and contribution of pollutant sources in non-flood season during 1990-2011

\begin{tabular}{|c|c|c|c|c|c|c|c|c|c|}
\hline \multirow{2}{*}{ 指标 } & \multicolumn{3}{|c|}{ 旋转后因子载荷 } & \multicolumn{3}{|c|}{ 因子得分系数矩阵 } & \multicolumn{3}{|c|}{ 污染贡献率/\% } \\
\hline & 因子 1 & 因子 2 & 因子 3 & 因子 1 & 因子 2 & 因子 3 & 因子 1 & 因子 2 & 因子 3 \\
\hline 电导率 & 0.91 & 0.23 & 0.19 & 0.30 & -0.02 & -0.07 & 87.7 & 21.5 & 18.7 \\
\hline 高锰酸盐指数 & -0.90 & 0.16 & -0.07 & -0.37 & 0.19 & 0.16 & & 15.4 & \\
\hline 硝酸盐氮 & 0.79 & 0.28 & 0.51 & 0.18 & 0.03 & 0.13 & 75.4 & 26.9 & 48.6 \\
\hline 总氮 & 0.74 & 0.32 & 0.55 & 0.14 & 0.06 & 0.16 & 70.6 & 31.3 & 52.7 \\
\hline 氨氮 & -0.16 & 0.96 & 0.21 & -0.24 & 0.43 & 0.19 & & 91.8 & 19.4 \\
\hline 浊度 & 0.31 & 0.88 & -0.05 & 0.02 & 0.33 & -0.05 & 29.8 & 84.4 & \\
\hline 氯化物 & 0.58 & 0.72 & -0.27 & 0.20 & 0.21 & -0.24 & 56.1 & 68.3 & \\
\hline 五日生化需氧量 & 0.11 & 0.17 & 0.92 & -0.17 & 0.10 & 0.49 & 10.8 & 16 & 88.4 \\
\hline $\mathrm{pH}$ & -0.31 & 0.40 & -0.83 & -0.01 & 0.17 & -0.37 & & 38.4 & \\
\hline 特征值 & 3.39 & 2.66 & 2.27 & & & & & & \\
\hline 方差贡献率 & $37.70 \%$ & $29.57 \%$ & $25.24 \%$ & & & & & & \\
\hline 累计贡献率 & $37.70 \%$ & $67.27 \%$ & $92.52 \%$ & & & & & & \\
\hline
\end{tabular}

每个监测点的因子得分及综合得分结果见表 4. 经过标准化处理的数据, 因子得分的均值为 0 , 标准差 为 1 , 正值表示高于平均水平,负值表示低于平均水平.汛期辛庄桥、石佛桥和金沟在因子 1 上的得分较高, 分别为 2.50 、 1.16 和 0.56 (表 4), 说明这几个监测点的水质在汛期受到农业营养物质的影响较大. 因子 2 得 分较高的监测点依次为大关桥、内湖和恒河, 其得分分别为 $1.47 、 0.71$ 和 0.70 , 表明这几个监测点主要受水 体内生物化学因素的影响. 因子 3 得分较高的监测点依次为金沟、水源九厂和内湖,其得分分别为 $1.87 、 1.79$ 和 0.49 , 表明这几个监测点的有机物污染相对严重. 综合得分最高的前三名依次是辛庄桥、内湖和大关桥. 
辛庄桥是密云水库上游潮河人库监测点, 大关桥是密云水库上游白河人库监测点, 汛期由于径流冲刷, 使得 上游污染物进人水体, 因而这 2 类监测点的综合因子得分较库区高. 内湖水体与主库区水体有一窄坝相隔, 当水位低于 $150 \mathrm{~m}$ 时, 通过侧渗、扩散等途径与主库区水发生物质交换, 内湖水体由于流动性差, 水质总体 较主库区水质差, 达到富营养化水平 ${ }^{[34]}$. 在汛期, 库区内的潮河、库西和白河监测点综合水质较好.

非汛期石佛桥、辛庄桥和水源九厂在因子 1 上得分较高,分别为 $2.08 、 1.45$ 和 0.44 , 说明这几个监测点 的水质在非汛期主要受农牧业排放因素的影响. 因子 2 得分较高的监测点依次为金沟、辛庄桥和内湖,其得 分分别为 $1.97 、 1.78$ 和 0.67 , 表明这几个监测点的水质主要受人类活动产生的影响. 因子 3 得分较高的监测 点依次为大关桥、辛庄桥和内湖, 其得分分别为 $1.49 、 1.28$ 和 1.14 , 其中, 大关桥和内湖在汛期和非汛期都受 到水体内生物化学因素的影响. 综合得分最高的前三名依次是辛庄桥、石佛桥和大关桥, 这 3 个监测点分别 位于密云水库上游潮河人库和白河人库, 综合水质相对较差. 在非汛期, 库区内库东、套里和恒河监的综合 水质较好.

表 4 监测点污染情况综合评分

Tab.4 Comprehensive score of monitoring sites contamination

\begin{tabular}{|c|c|c|c|c|c|c|c|c|c|}
\hline \multicolumn{5}{|c|}{ 汛期 } & \multicolumn{5}{|c|}{ 非汛期 } \\
\hline 监测点 & $F_{1}$ 得分 & $\mathrm{F}_{2}$ 得分 & $F_{3}$ 得分 & $F$ 得分 & 监测点 & $F_{1}$ 得分 & $F_{2}$ 得分 & $F_{3}$ 得分 & $F$ 得分 \\
\hline 辛庄桥 & 2.50 & 0.19 & -0.13 & 1.23 & 辛庄桥 & 1.45 & 1.78 & 1.28 & 1.51 \\
\hline 内湖 & -0.07 & 0.71 & 0.49 & 0.30 & 石佛桥 & 2.08 & -0.66 & 0.02 & 0.64 \\
\hline 大关桥 & -0.18 & 1.47 & -1.66 & 0.13 & 大关桥 & -0.05 & -0.24 & 1.49 & 0.31 \\
\hline 金沟 & 0.56 & -1.59 & 1.87 & 0.04 & 金沟 & -0.02 & 1.97 & -1.50 & 0.21 \\
\hline 石佛桥 & 1.16 & -1.20 & -0.72 & 0.01 & 内湖 & -1.80 & 0.67 & 1.14 & -0.21 \\
\hline 库东 & -0.58 & 0.59 & -0.25 & -0.11 & 水源九厂 & 0.44 & 0.13 & -1.72 & -0.25 \\
\hline 套里 & -0.68 & 0.26 & 0.22 & -0.20 & 潮河 & -0.17 & -0.95 & 0.26 & -0.30 \\
\hline 水源九厂 & 0.23 & -1.80 & 1.79 & -0.20 & 白河 & -0.09 & -1.14 & 0.22 & -0.34 \\
\hline 恒河 & -0.90 & 0.70 & -0.29 & -0.23 & 库西 & -0.26 & -0.61 & -0.18 & -0.35 \\
\hline 白河 & -0.69 & 0.34 & -0.45 & -0.29 & 恒河 & -0.54 & -0.44 & -0.07 & -0.38 \\
\hline 库西 & -0.74 & 0.27 & -0.42 & -0.34 & 套里 & -0.20 & -0.47 & -0.60 & -0.40 \\
\hline 潮河 & -0.60 & 0.06 & -0.44 & -0.34 & 库东 & -0.83 & -0.05 & -0.33 & -0.44 \\
\hline
\end{tabular}

\section{4 水质时间分布特征}

根据密云水库管理处的水质监测数据和聚类分析结果, 选取白河人库 (大关桥)、潮河人库 (辛庄桥) 作 为人库水质监测点, 库西、库东和内湖作为库区水质的代表性监测点, 水源九厂为出库水质监测点, 对密云 水库 1990-2011 年共 22 年的水质年际变化进行分析.

除内湖以外,其余 5 个监测点高锰酸盐指数的变化趋势基本一致(图 3a). 1991-1995 年呈上升趋势, 后缓慢下降,趋于平缓, 2000-2004 年间内湖水体中的高锰酸盐指数出现大幅上升, 明显高于其他监测点. 刘晓端等于 2001 年对密云水库的营养状况进行调研, 发现密云水库主库区水体呈中营养化, 而内湖水体呈 富营养化 ${ }^{[34]}$, 这可能是由于早期在内湖进行网箱养鱼投饵和鱼类粪便的积累所导致的水质恶化引起的 ${ }^{[35]}$.

1990-2002 年间, 各监测点五日生化需氧量的变化趋势不同且年际波动较大 (图 3b). 2003 年以后, 6 个监测点五日生化需氧量的变化趋势一致: 在 2005 年同时出现一个高峰,之后迅速回落,2006 年以后一直 保持平稳. 这可能是由于 2006 年以后, 北京市和河北在潮白河流域实施 “稻改旱” 工程 ${ }^{[32]}$, 有效减少了上游 五日生化需氧量, 同时有效减少了库区浓度. 此外, 内湖监测点近年来有略微上升的趋势, 有污染的潜在风 险, 还需进一步加强管理.

1996 年以前, 各监测点总磷浓度呈现波动上涨, 1996-2000 年各监测点总磷浓度迅速回落 (图 3c). 根 据水文频率分析 (皮尔逊 3 型曲线法) 判断, 2002 年为相对枯水年 ${ }^{[36]}$, 上游来水量较低, 潮白河人库总磷浓 度也相对较低. 2004 年为相对丰水年 ${ }^{[37]}$, 随着上游径流量的增加, 潮白河人库的总磷浓度同时出现一个小 高峰. 这主要是由于密云水库中 $94 \%$ 的总磷是通过上游河流来水带人水库中, 并且主要为颗粒态磷在降水 
驱动下随上游径流携带的泥沙进人水体, 因此上游河流输人对库区总磷滞留占最主要的贡献 ${ }^{[38]}$. 2000 年以 后, 潮河人库、白河人库和内湖的总磷浓度出现小幅波动但最终浓度降低到和库区内一致, 库区内总磷浓度 基本保持平稳. 这可能是由于该流域加强管理措施和治理力度, 使得人库径流中总磷浓度减少, 因而库区水 质得以好转 ${ }^{[39]}$. 此外,2006 年开始的 “稻改旱”工程和 2008 年开始的水华防治工程在控磷方面也显示出显 著的效果.

潮河人库的总氮浓度呈明显增加的趋势, 总氮浓度均值约为 $4 \mathrm{mg} / \mathrm{L}$ ( 图 3d). 白河人库总氮浓度一直小 幅上涨, 自 1999 年后大约为 $2 \mathrm{mg} / \mathrm{L}$. 库区内监测点的总氮浓度基本保持稳定, 近 20 年来基本维持在 $1 \mathrm{mg} / \mathrm{L}$ 附近. 研究发现, 密云水库主要人库河段总氮浓度的变化规律与硝态氮浓度类似 ${ }^{[40]}$, 表明总氮的增加主要 是受硝态氮增加的影响. 密云水库上游尤其是潮河流域地下水硝态氮污染严重 ${ }^{[41]}$, 硝态氮随着降水和灌溉 等淋溶作用进人地下水, 再补给到河流, 可能是潮河人库总氮浓度偏高的主要原因 ${ }^{[32]}$.
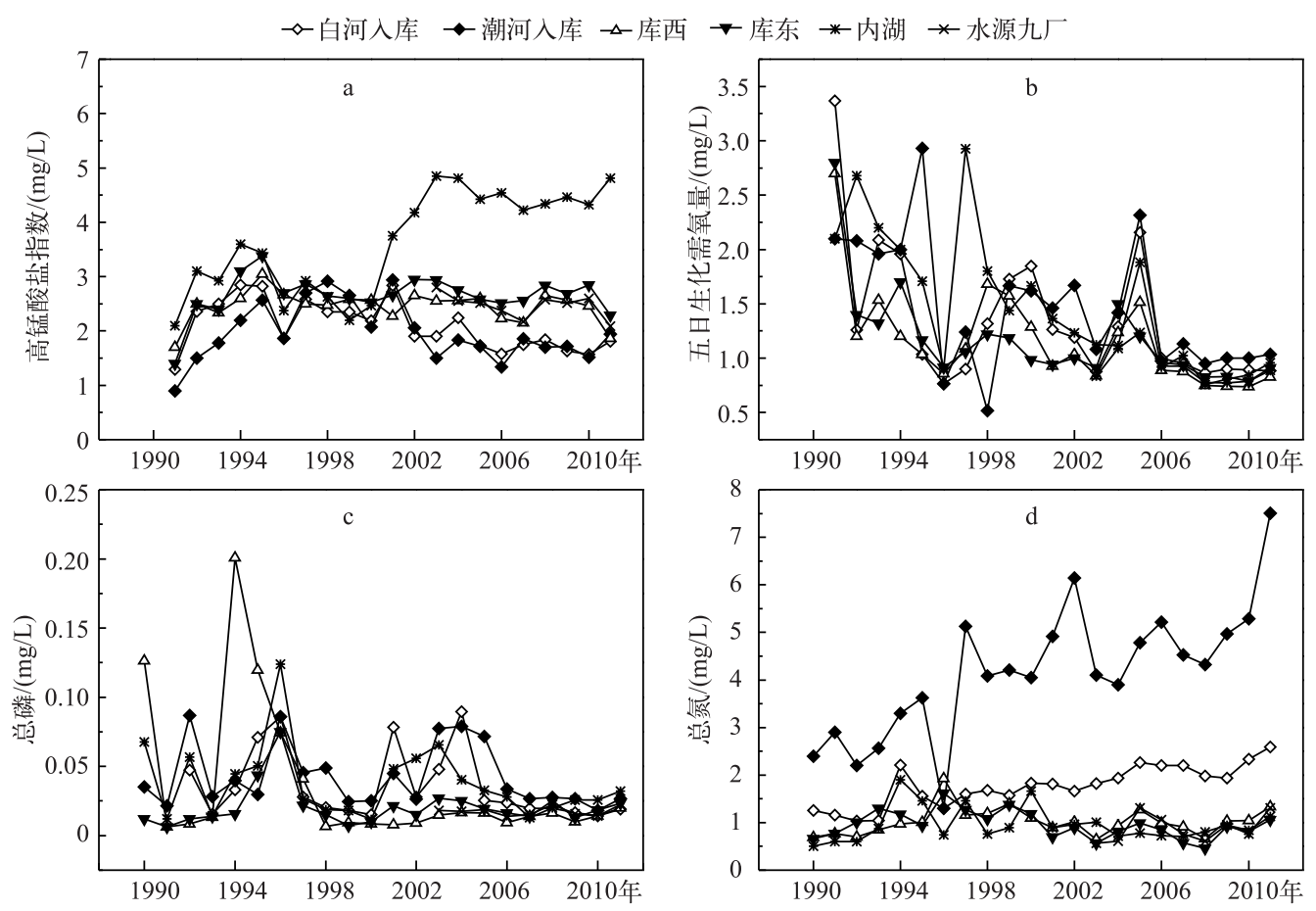

图 3 1990－2011 年密云水库主要水质指标年际变化

Fig.3 Interannual variation of main water quality index in Miyun Reservoir during 1990 - 2011

\section{5 季节性 Kendall 检验}

季节性 Kendall 浓度检验结果见表 5. 检验统计量 $S$ 为 “一致对数” $P$ ( 随时间增长后面的值高于前面的 值) 与 “不一致对数” $M$ (随时间的增长后面的值低于前面的值) 的差值. $Z$ 为标准方差, 通常取显著性水平 $\alpha$ 为 0.1 和 0.01 , 当 $\alpha \leqslant 0.01$ 时, $|Z|>2.567$, 说明检验具有高度显著性水平; 当 $0.01<\alpha \leqslant 0.1$ 时, $1.645<|Z|<$ 2.567 , 说明检验效果显著. $\tau$ 为相关系数, 若 $\tau$ 为正, 则表明水质序列具有显著或高度显著上升趋势; 若 $\tau$ 为 负, 说明水质序列趋势是下降的; 当 $\tau$ 为零时, 表明无趋势 ${ }^{[42-43]}$. 白河人库段总磷浓度和高镇酸盐指数无明 显升降趋势, 总氮浓度显著上升, 五日生化需氧量高度显著下降. 潮河人库段总氮浓度高度显著上升, 总磷 浓度高度显著下降, 高锰酸盐指数无明显升降趋势, 五日生化需氧量显著下降. 库东总氮浓度、总磷浓度和 高锰酸盐指数均无明显升降趋势, 五日生化需氧量显著下降. 与潮白河人库水质变化相比, 库区水质变化趋 势较小, 这可能是因为库区蓄水量大, 对人库水质指标起到了稀释的作用, 因而浓度变化不大. 密云水库的 总氮主要来自潮河流域 ${ }^{[4]}$, 这是因为潮河流域人口密度大, 农业集约化程度高, 降雨径流的冲刷使得大量化 
肥和禽畜粪便流失汇人河道, 最终进人水库 ${ }^{[45]}$. 另一方面, 总氮浓度在潮河人库处呈上升趋势, 而在库区内 无明显升降趋势, 除了稀释的原因外还可能是因为库区内水体具有一定的自净作用, 因而即便人库处浓度 呈上升趋势库区内的总氮浓度仍能维持稳定. 3 个监测点的高锰酸盐指数都无明显升降趋势, 这说明目前密 云水库水污染防治和水资源保护工作控制的较好, 可继续维持或进一步加强治理. 白河人库的五日生化需 氧量呈高度显著下降趋势, 潮河人库和库东的五日生化需氧量呈显著下降趋势, 说明密云水库水质无论是 上游人库还是库区都整体趋好.

表 5 季节性 Kendall 浓度检验结果

Tab.5 Results of seasonal Kendall concentration analysis

\begin{tabular}{lcrcccc}
\hline 监测点 & 水质指标 & $S$ & $\tau$ & $Z$ & $r$ & 趋势 \\
\hline 白河人库 & 总氮 & 65 & 0.193 & 2.287 & 0.0583 & 显著上升 \\
& 总磷 & -44 & -0.131 & -1.642 & 0 & 无明显升降 \\
& 高锰酸盐指数 & -18 & -0.054 & -0.623 & 0 & 无明显升降 \\
& 五日生化需氧量 & -123 & -0.399 & -4.816 & -0.04 & 高度显著下降 \\
潮河人库 & 总氮 & 126 & 0.375 & 4.47 & 0.3025 & 高度显著上升 \\
& 总磷 & -136 & -0.405 & -4.96 & -0.0051 & 高度显著下降 \\
& 高锰酸盐指数 & -2 & -0.006 & -0.036 & 0 & 无明显升降 \\
& 五日生化需氧量 & -59 & -0.192 & -2.261 & -0.02 & 显著下降 \\
& 总氮 & 23 & 0.113 & 1.028 & 0.0233 & 无明显升降 \\
& 总磷 & -17 & -0.084 & -0.78 & 0 & 无明显升降 \\
& 高锰酸盐指数 & 0 & 0 & 0 & 0 & 无明显升降 \\
& 五日生化需氧量 & -50 & -0.246 & -2.416 & -0.025 & 显著下降 \\
\hline
\end{tabular}

虽然季节性 Kendall 检验的结果可以反映某个水质指标的升降结果及数据符合该升降趋势的程度,但 无法反映所判断趋势的大小, 还需通过季节性 Kendall 斜率 $r$ 进一步分析 ${ }^{[30]}$. 其中, 潮河人库总氮浓度的上 升速率最快, 平均每年上升 $0.3025 \mathrm{mg} / \mathrm{L}$. 其次是白河人库和库东, 平均每年分别上升 0.0583 和 $0.0233 \mathrm{mg} / \mathrm{L}$. 潮河人库的总磷浓度平均每年下降 $0.0051 \mathrm{mg} / \mathrm{L}$, 白河人库和库东的总磷浓度都无明显升降. 3 个监测点的 高镇酸盐指数都无明显升降趋势. 由于季节性 Kendall 检验法最终得到的是一个多年的趋势分析结果, 而没 有反映中间的升降过程, 如监测指标在某一季节 (或月份) 表现为上升趋势, 而另一季节 (或月份) 表现为下 降趋势, 则相互抵消后最终分析结果也有可能为无明显升降趋势 ${ }^{[30]}$. 白河人库的五日生化需氧量下降速率 最快, 平均每年下降 $0.040 \mathrm{mg} / \mathrm{L}$. 其次是库东和潮河人库, 平均每年分别下降 0.025 和 $0.020 \mathrm{mg} / \mathrm{L}$.

2004-2011 年潮、白河人库监测点水环境因子浓度与流量的关系见图 4. 一般而言, 对于点源污染物, 随着流量的增加, 由于稀释作用浓度会降低. 对于非点源污染物, 在汛期当遇到普通降雨时, 仅有部分非点 源污染物进人河流, 其浓度可能小于河道本身浓度, 从而起到稀释作用. 当遇到大暴雨时, 随着流量的快速 增加, 大量非点源物质迁移到水体中, 使得浓度增加 ${ }^{[32]}$. 其中, 对于白河人库监测点, 高锰酸盐指数随着流 量的增加而增加, 说明高锰酸盐指数主要来自于非点源污染. 随着流量的增大, 总氮、总磷和五日生化需氧 量浓度都没有明显增高, 说明白河流域这 3 个指标的潜在非点源污染较少. 对于潮河而言, 随着流量的增 加, 总氮、总磷、高锰酸盐指数和五日生化需氧量的浓度都增大, 其中总氮和高锰酸盐指数对流量的变化最 为敏感. 由于潮河流域人类活动和农业集约化程度远高于白河流域, 使得水分利用、点源排放、农田面积和 化肥使用都远远高于白河流域, 因而潮河流域对流量的变化更加敏感, 潮河流域的潜在非点源污染较白河 流域多 ${ }^{[32]}$. 潮、白河人库的其他监测指标均不符合随流量增加浓度降低的规律, 因而可以判断水环境指标 浓度的变化主要是非点源作用的结果.

为了判断造成水质变化的原因, 对各监测指标进一步进行了季节性 Kendall 流量调节检验, 结果见表 6 . 其中 $r^{2}$ 为反映流量和污染物浓度相关关系的参数. 比较表 5 和表 6 可以发现, 除白河人库的总氮和总磷外, 其他监测指标的变化趋势经流量调节前后基本一致, 表明流量并不是引起水质趋势变化的主要因素, 水质 的变化主要是由于污染源变化而引起. 白河人库和潮河人库的总氮浓度均呈高度显著上升趋势, 表明来源 

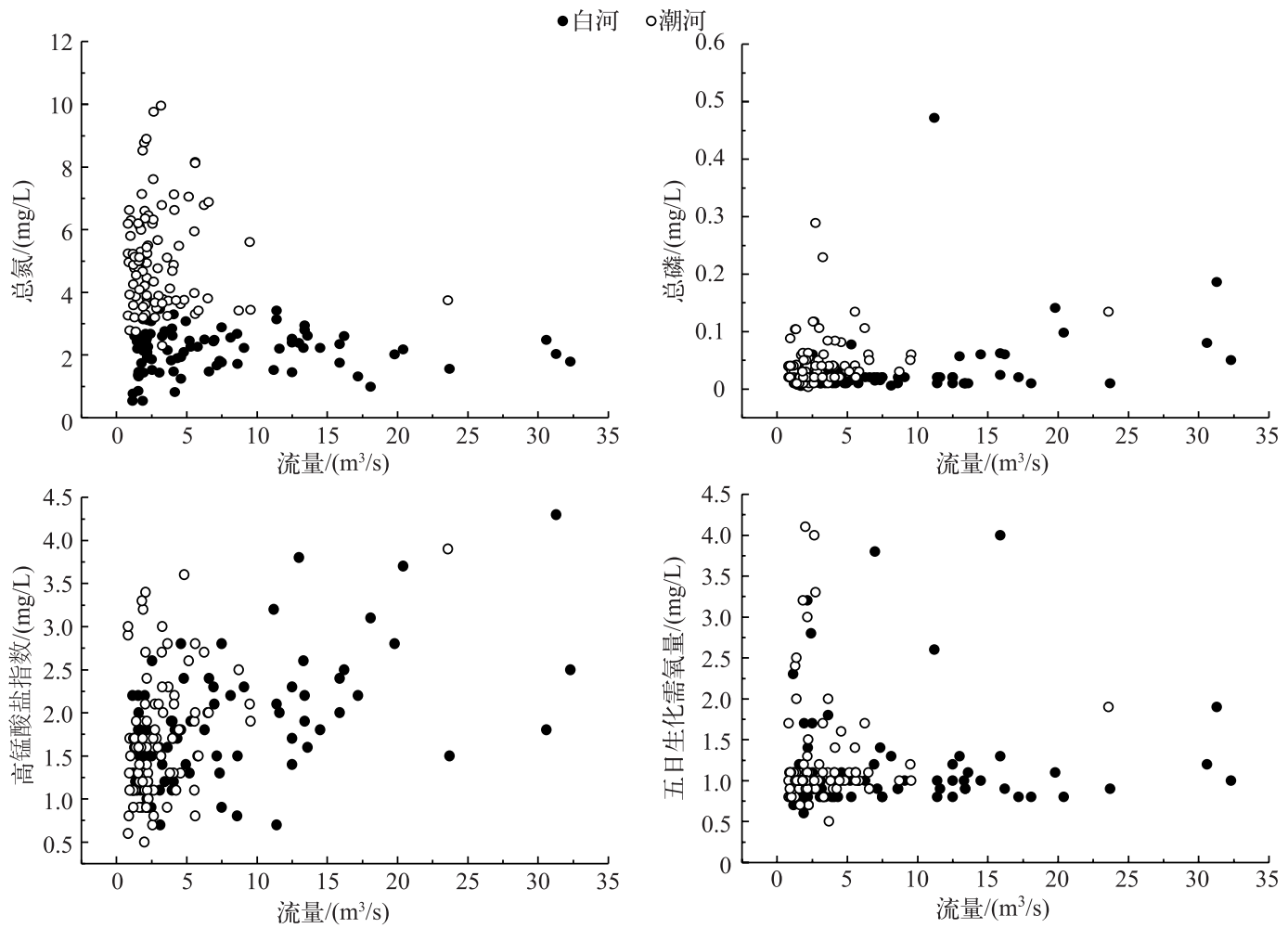

图 4 2004-2011 年潮、白河人库监测点水环境因子浓度与流量的关系

Fig.4 The relationships between pollutant concentrations and the flow in water quality monitoring sites in Chaohe and Baihe rivers during $2004-2011$

有所增加. 高锰酸盐指数无明显升降. 总磷和五日生化需氧量呈显著或高度显著下降趋势, 表明来源有所 减少.

表 6 季节性 Kendall 流量调节浓度检验结果

Tab.6 Results of flow regulated seasonal Kendall concentration analysis

\begin{tabular}{lcccccc}
\hline 监测点 & 水质指标 & $S$ & $\tau$ & $Z$ & $r^{2}$ & 趋势 \\
\hline 白河人库 & 总氮 & 74 & 0.22 & 2.607 & 0.0009 & 高度显著上升 \\
& 总磷 & -55 & -0.164 & -1.93 & 0.1249 & 显著下降 \\
& 高锰酸盐指数 & -22 & -0.065 & -0.75 & 0.3038 & 无明显升降 \\
& 五日生化需氧量 & -114 & -0.407 & -4.421 & 0.0096 & 高度显著下降 \\
潮河人库 & 总氮 & 142 & 0.423 & 5.036 & 0.0046 & 高度显著上升 \\
& 总磷 & -146 & -0.435 & -5.179 & 0.0656 & 高度显著下降 \\
& 高锰酸盐指数 & -2 & -0.006 & -0.036 & 0.1678 & 无明显升降 \\
& 五日生化需氧量 & -52 & -0.169 & -1.902 & 0.0021 & 显著下降 \\
\hline
\end{tabular}

\section{3 结论}

1) 汛期密云水库库区水质主要受到农业营养物质的影响, 其次为水体内生物化学因素和有机物的影 响. 农业营养物质主要影响氯化物、电导率、氨氮、总氮和硝酸盐氮. 生物化学因素主要影响五日生化需氧 量、硝酸盐氮、总氮和浊度. 有机物影响因素主要影响高锰酸盐指数和五日生化需氧量. 非汛期密云水库库 
区水质主要受到农牧业排放因素的影响, 其次为人类活动因素和水体生物化学因素的影响. 农牧业排放因 素主要影响电导率、硝酸盐氮和总氮. 人类活动主要影响氨氮和浊度,生物化学因素主要影响五日生化需氧 量、总氮和硝酸盐氮. 因子得分综合评价显示汛期辛庄桥、内湖和大关桥综合水质较差, 潮河、库西和白河综 合水质较好. 非汛期辛庄桥、石佛桥和大关桥综合水质较差,库东、套里和恒河综合水质较好.

2) 1990-2011 年密云水库主要水质指标年际变化表明: 高锰酸盐指数 (除内湖外) 1991-1995 年呈上 升趋势, 后缓慢下降,趋于平缓. 1990-2002 年间, 各监测点五日生化需氧量变化趋势不同且年际波动较大. 2003 年以后, 所有监测点五日生化需氧量的变化趋势逐渐一致, 在 2005 年同时出现一个高峰, 之后迅速回 落, 并保持平稳. 1996 年以前, 各监测点总磷浓度呈现波动上涨, 1996 年后迅速回落并逐渐趋向平稳. 19902011 年整个期间各监测点总氮浓度基本保持稳定, 潮河人库的总氮浓度明显高于其他监测点. 总体上内湖 水质污染较为严重, 还需进一步加强管理.

3) 季节性 Kendall 检验结果表明: 白河人库段的水质高锰酸盐指数和总磷无明显升降趋势, 总氮浓度显 著上升, 五日生化需氧量高度显著下降. 潮河人库段高锰酸盐指数无明显升降趋势, 总氮浓度高度显著上 升, 总磷浓度高度显著下降, 五日生化需氧量显著下降. 库东总氮、总磷和高锰酸盐指数均无明显升降趋势, 五日生化需氧量显著下降. 除白河人库的总氮和总磷外, 其他监测指标的变化趋势经流量调节前后基本一 致,表明流量并不是引起水质趋势变化的主要因素,水质的变化主要是由于污染源变化而引起.

\section{4 建议}

1)近年来密云水库水位持续下降, 蓄水量减少使得水库的纳污能力和自净能力明显降低. 2015 年 “南 水北调” 中线工程顺利通水, 来水经由密云水库调蓄工程输人密云水库, 同时减少密云水库出库水量, 能提 高密云水库水位, 改善低水位运行现状, 加强自身恢复能力.

2) 源解析结果可知,农业营养物质排放对水质影响最大. 应发展与水源保护相适应的生态农业, 调整农 业结构,转变农业生产方式,合理调整产业布局,减少化肥农药的使用,控制面源污染.

3) 建立水库周边污水及垃圾处理设施, 避免生活污水直接排人河道, 提高企业污水处理能力, 加强村镇 垃圾收集和无害化处理.

4) 综合水质分析结果表明, 无论汛期还是非汛期潮、白河人库监测点的综合水质都较差. 要加强潮、白 河人库口生态湿地建设和保护, 充分发挥水生植物的水质净化功能, 减少上游污染输人.

5) 库区实行封闭管理,减少生产建设和旅游等人类活动的影响. 在河岸带种植可有效截留降雨地表径 流的植被, 减少径流污染物进人河道.

6) 建立智能水库管理系统. 以已有监测数据为基础, 充分利用信息化技术和数学模型, 构建密云水库流 域水环境安全保障平台,进行洪水预报、水质安全及富营养化预警和生物预警. 增强决策的科学性和预见 性, 提高水库的应急反应和处置能力.

\section{5 参考文献}

[ 1 ] Chen Yongcan, Zhang Baoxu, Li Yuliang. Study on model for vertical distribution of water temperature in Miyun Reservoir. Journal of Hydraulic Engineering, 1998, (9) : 14-20 (in Chinese with English abstract). [ 陈永灿, 张宝旭, 李玉梁. 密 云水库垂向水温模型研究. 水利学报, 1998, (9) : 14-20.]

[ 2 ] Su Baolin, Wang Jianping, Jia Haifeng et al. Non-point source modeling system of the Miyun Reservoir watershed. Journal of Tsinghua University: Science and Technology, 2006, 46(3) : 355-359(in Chinese with English abstract). [苏保林, 王 建平, 贾海峰等. 密云水库流域非点源模型系统. 清华大学学报: 自然科学版, 2006, 46(3): 355-359.]

[ 3 ] Wang Qingsuo, Mei Xurong, Zhang Yanqin et al. Review of water quality of Miyun Reservoir. Journal of Agricultural Science and Technology, 2009, 11 (1) : 45-50 (in Chinese with English abstract). [王庆锁, 梅旭荣, 张燕卿等. 密云水库 水质研究综述. 中国农业科技导报, 2009, 11(1): 45-50.]

[ 4 ] Liu Xia, Du Guisen, Zhang Hui et al. Phytoplankton and nutrient degree of water body in Miyun Reservoir. Research of Environmental Sciences, 2003, 16(1) : 27-29(in Chinese with English abstract). [刘霞, 杜桂森, 张会等. 密云水库的 浮游植物及水体营养程度. 环境科学研究, 2003, 16(1): 27-29] 
[ 5 ] Du Guisen, Liu Xiaorui, Liu Xia et al. Analysis on trophic state of water body in Miyun Reservoir. Acta Hydrobiologica Sinica, 2004, 28(2) : 191-196(in Chinese with English abstract). [ 杜桂森, 刘晓端, 刘霞等. 密云水库水体营养状 态分析. 水生生物学报, 2004, 28(2): 191-196]

[ 6 ] Zhang Lingsong, Liu Tingliang, Meng Fansheng et al. Multivariate statistical analysis of Songhua River water quality. Environmental Pollution and Control, 2013, 35(9): 28-34(in Chinese with English abstract). [张铃松, 刘廷良, 孟凡生 等. 松花江水质的多元统计分析. 环境污染与防治, 2013, 35(9): 28-34.]

[ 7 ] Sun Guohong, Shen Yue, Xu Yingming et al. Water quality assessment of Yellow River based on multivariate statistical analysis. Journal of Agro-Environment Science, 2011, 30(6): 1193-1199(in Chinese with English abstract). [孙国红, 沈 跃, 徐应明等. 基于多元统计分析的黄河水质评价方法. 农业环境科学学报, 2011, 30(6) : 1193-1199.]

[ 8 ] Yu Hui, Yan Shuwen, Xu Jun. Multivariate statistical analysis of water quality in the inflow and outflow rivers of Lake Taihu. Resources and Environment in the Yangtze Basin, 2010, 19(6): 696-702(in Chinese with English abstract). [余 辉, 燕姝雯, 徐军. 太湖出人湖河流水质多元统计分析. 长江流域资源与环境, 2010, 19(6) : 696-702.]

[ 9 ] Ge Xiaoli, Liu Xiaoduan, Pan Xiaochuan et al. The geochemical characteristics of water body in Miyun Reservoir. Rock and Mineral Analysis, 2003, 22(1): 44-48(in Chinese with English abstract). [葛晓立, 刘晓端, 潘小川等. 密云水 库水体的地球化学特征. 岩矿测试, 2003, 22(1): 44-48.]

[10] Li Huimin, Meng Fanyan, Du Guisen et al. Analysis on the phytoplankton and water quality in eastern and western Miyun Reservoir. J Lake Sci, 2007, 19(2) : 146-150( in Chinese with English abstract). DOI : 10.18307/2007.0206. [李慧敏, 孟凡艳, 杜桂森等. 密云水库东西库区的水质与浮游藻类分析. 湖泊科学, 2007, 19(2): 146-150.]

[11] Xu Qing, Yang Tianxing, Liu Xiaoduan et al. Analysis and prediction of eutrophication for Miyun Reservoir. Journal of Jilin University: Earth Science Edition, 2003, 33(3) : 315-318 (in Chinese with English abstract). [徐清, 杨天行, 刘晓 端等. 密云水库总磷的富营养化分析与预测. 吉林大学学报 (地球科学版), 2003, 33(3): 315-318.]

[12] Liang Xiujuan, Xiao Changlai, Yang Tianxing et al. Research of the influence factor of nitrogen distribution and migration in Miyun Reservoir. Science in China (Series D), 2006, 35(A01) : 272-280( in Chinese). [梁秀娟, 肖长来, 杨天行 等. 密云水库中氮分布及迁移影响因素研究. 中国科学: D 辑: 地球科学, 2006, 35(A01) : 272-280.]

[13] Shi Zhimin, Su Huiyan. Water quality trend analysis of Daling River( Chaoyang Section) based on seasonal Kendal analysis. Ground Water, 2009, 31(3) : 88, 101 (in Chinese). [时志敏, 苏慧艳. 基于季节性 Kendal 法的大凌河朝阳段水 质趋势分析. 地下水, $2009, \mathbf{3 1}(3): 88,101$.]

[14] Zhang Wangshou, Li Xiaoxiu, Wang Xiaoyan et al. Temporal and spatial variations of water pollution in Wuqing section of Beiyunhe River. Acta Scientiae Circumstantiae, 2012, 32(4) : 836-846(in Chinese with English abstract). [张汗寿, 李 晓秀, 王晓燕等. 北运河武清段水污染时空变异特征. 环境科学学报, 2012, 32(4): 836-846.]

[15] Wu Yuhong, Tian Xiaohong, Nan Xiongxiong et al. Evaluation of soil quality under conservation tillage via factor and cluster analyses. Chinese Journal of Eco-Agriculture, 2010, 18(2): 223-228 (in Chinese with English abstract). DOI: 10. 3724/SP.J.1011.2010.00223. [ 吴玉红, 田霄鸿, 南雄雄等. 基于因子和聚类分析的保护性耕作土壤质量评价研究. 中国生态农业学报, 2010, 18(2) : 223-228.

[16] Xue Wei ed. Data Analysis based on SPSS. Beijing: China Renmin University Press, 2006(in Chinese). [薛薇. 基于 SPSS 的数据分析. 北京: 中国人民大学出版社, 2006.]

[17] Li Yilu, Zhang Yuhu, Jia Haifeng et al. Spatio-temporal characteristics and source identification of water pollutants in ancient town of Suzhou. Acta Scientiae Circumstantiae, 2014, 34(4) : 1032-1044 (in Chinese with English abstract). [李 义禄, 张玉虎, 贾海峰等. 苏州古城区水体污染时空分异特征及污染源解析. 环境科学学报, 2014, 34(4): 1032-1044.]

[18] Liu Y, Guo H, Yang P et al. Exploring the influence of lake water chemistry on chlorophyll $a$ : A multivariate statistical model analysis. Ecological Modelling, 2010, 221(4) : 681-688. DOI: 10.1016/j.ecolmodel.2009.03.010.

[19] Zhou F, Huang GH, Guo H et al. Spatio-temporal patterns and source apportionment of coastal water pollution in eastern Hong Kong. Water Research, 2007, 41(15) : 3429-3439. DOI: 10.1016/j.watres.2007.04.022.

[20] Ma Xiping, Lv Xiaofei, Zhang Lihong et al. Assessment of water quality and source apportionment of pollution in Liao River Basin. Water Resources Protection, 2011, 27(4) : 1-4, 73(in Chinese with English abstract). [马溪平, 吕晓飞, 张 利红等. 辽河流域水质现状评价及其污染源解析. 水资源保护, 2011, 27(4): 1-4, 73. ]

[21] Thurston GD, Spengler JD. A quantitative assessment of source contributions to inhalable particulate matter pollution in 
metropolitan Boston. Atmospheric Environment(1967) , 1985, 19(1) : 9-25. DOI: 10.1016/0004-6981( 85)90132-5.

[22] Morales MM, Martı P, Llopis A et al. An environmental study by factor analysis of surface seawaters in the Gulf of Valencia( Western Mediterranean). Analytica Chimica Acta , 1999, 394(1) : 109-117. DOI: 10.1016/S0003-2670(99) 00198-1.

[23] Zhang Y, Guo F, Meng W et al. Water quality assessment and source identification of Daliao river basin using multivariate statistical methods. Environmental Monitoring and Assessment, 2009, 152(1): 105-121. DOI: 10.1007/s10661-0080300-z.

[24] Zhou F, Guo H, Liu L. Quantitative identification and source apportionment of anthropogenic heavy metals in marine sediment of Hong Kong. Environmental Geology, 2007, 53(2) : 295-305. DOI : 10.1007/s00254-007-0644-7.

[25] Miller SL, Anderson MJ, Daly EP et al. Source apportionment of exposures to volatile organic compounds. I. Evaluation of receptor models using simulated exposure data. Atmospheric Environment, 2002, 36(22) : 3629-3641. DOI: 10.1016/ S1352-2310 ( 02) 00279-0.

[26] Sun Song. Application of the seasonal Kendall's test method in water quality tendency analysis of Huangtan Reservoir. Guangzhou Environmental Science, 2012, 26(2) : 31-33( in Chinese with English abstract). [孙松. 季节性 Kendall 检验 法在黄坛水库水质趋势分析中的应用. 广州环境科学, 2012, 26(2) : 31-33.]

[27] Chen Wenle. Comparative analysis of water quality change trend assesment based on seasonal Kendall's test method and Grey Situation Decision-comprehensive evaluation index method. Gansu Water Conservancy and Hydropower Technology, 2010, 46(5) : 20-22 (in Chinese). [陈文乐. 季节性肯达尔检验法和灰色局势决策-综合评价指数法对水质变化趋 势评价的对比分析. 甘肃水利水电技术, 2010, 46(5): 20-22.]

[28] Helsel DR, Frans LM. Regional Kendall test for trend. Environmental Science \& Technology, 2006, 40( 13) : 4066-4073. DOI : $10.1021 / \mathrm{es} 051650 \mathrm{~b}$.

[29] Zhang Qingqiang. Application of Seasonal Kendall's test method in water quality trend analysis of tianjin surface water function areas. Journal of Anhui Agricultural Sciences, 2013, 41(21): 9016-9017(in Chinese with English abstract). [张庆 强. 季节性 Kendall 检验在天津地表水功能区水质趋势分析中的应用研究. 安徽农业科学, 2013, 41(21): 9016-9017.

[30] Yang Jianbo, Zhang Yanzhai. Application of seasonal Kendall's test method in water quality trend analysis of Huai River Basin. Hydrology, 1991，(5): 44-47( in Chinese with English abstract). [杨建波, 张炎斋. 季节性肯达尔检验法在淮 河流域水质趋势分析中的应用. 水文，1991，(5):44-47.]

[31] Wang Xiaoyan, Yuan Yingdong. Study on phosphorus adsorption and diffusion of sediment in Miyun Reservoir. Journal of Capital Normal University: Natural Science Edition, 2005, 18(3) : 85-90(in Chinese with English abstract). [王晓燕, 苑迎冬. 密云水库底质特征及吸附、释放磷的实验研究. 首都师范大学学报 (自然科学版), 2005, 18(3): 85-90.]

[32] Li Wenzan, Li Xuyong, Wang Xiaoxue. Trends in the total nitrogen concentration and the major influencing factors in the main rivers flowing into the Miyun Reservoir in recent 20 years. Acta Scientiae Circumstantiae, 2013, 33(11) : 3047-3052 (in Chinese with English abstract). [李文赞, 李叙勇, 王晓学. 20 年来密云水库主要人库河流总氮变化趋势和影响 因素. 环境科学学报, 2013, 33(11): 3047-3052.]

[33] Zhao Jie, Xu Zongxue, Liu Xingcai et al. Source apportionment in the Liao River Basin. China Environmental Science, 2013, 33(5) : 838-842(in Chinese with English abstract). [赵洁, 徐宗学, 刘星才等. 辽河河流水体污染源解析. 中 国环境科学, 2013, 33(5):838-842.]

[34] Liu Xiaoduan, Ge Xiaoli, Xu Qing et al. Analysis on eutrophication status of inner lake in Miyun Reservoir. J Lake Sci, 2002, 14(4) : 331-336( in Chinese with English abstract). DOI:10.18307/2002.0406. [刘晓端, 葛晓立, 徐清等. 密 云水库内湖富营养化现状分析. 湖泊科学, 2002, 14(4): 331-336.]

[35] Du Guisen, Han Zhiquan, Meng Fanyan et al. Study on effects of net-cage fishculture on water quality. Journal of Capital Normal University: Natural Science Edition, 1993, 14(4) : 11-15( in Chinese with English abstract). [杜桂森, 韩志泉, 孟繁艳等. 网箱养鱼对水质影响的研究. 首都师范大学学报: 自然科学版, 1993, 14(4): 11-15.]

[36] Zeng Q, Qin L, Li X. The potential impact of an inter-basin water transfer project on nutrients( nitrogen and phosphorus) and chlorophyll a of the receiving water system. Science of the Total Environment, 2015, 536: 675-686. DOI: 10.1016/j. scitotenv.2015.07.042.

[37] Shen Xiao, Du Xinzhong, Jia Dongmin et al. The influence of upstream input on phosphorus retention in Miyun Reservoir. Acta Scientiae Circumstantiae, 2015, 35(10) : 3114-3120(in Chinese with English abstract). [申校，杜新忠，贾东民 
等. 人库河流输人对密云水库磷滞留过程的影响分析. 环境科学学报, 2015, 35(10): 3114-3120.]

[38 ] Wang Xiaoyan, Hu Qiuju, Zhu Fengyun et al. Loss of nutrients in runoff and soil in the watershed of Miyun Reservoir-As a example of shixia experimental area. Journal of Capital Normal University: Natural Science Edition, 2001, 22(2) : 7985( in Chinese with English abstract). [王晓燕, 胡秋菊, 朱风云等. 密云水库流域降雨径流土壤中氮磷流失规 律一以石匣试验区为例. 首都师范大学学报(自然科学版), 2001, 22(2): 79-85.]

[39] Liang Bo. Total amount control on non-point pollution from the watershed of Miyun Reservoir[Dissertation]. Beijing: Capital Normal University, 2005( in Chinese with English abstract). [梁博. 密云水库流域非点源污染总量控制研究 [ 学 位论文]. 北京: 首都师范大学, 2005.]

[40] Yu Yilei, Wang Qingsuo. Analysis of seasonal changes of water quality in Miyun Reservoir and reaches of its main influents. Agricultural Meteorology, 2008, 29(4) : 432-435(in Chinese with English abstract). [于一雷, 王庆锁. 密云水库 及其主要河流人库河段水质的季节变化. 中国农业气象, 2008, 29(4) : 432-435.]

[41] Wang Qingsuo, Sun Dongbao, Hao Weiping et al. Nitrate concentration distribution in groundwater of the Miyun Reservoir watershed. Acta Pedologica Sinica, 2011, 48(1): 141-150( in Chinese with English abstract). [王庆锁, 孙东宝, 郝卫 平等. 密云水库流域地下水硝态氮的分布及其影响因素. 土壤学报, 2011, 48(1): 141-150.]

[42] Jiang Tao, Zhang Xiaolei, Chen Xiaohong. The characteristics of water quality change for the main control sections in the middle and upper reaches of East River. J Lake Sci, 2009, 21(6) : 873-878( in Chinese with English abstract). DOI : 10. 18307/2009.0618. [江涛, 张晓否, 陈晓宏. 东江中上游主要控制断面水质变化特征. 湖泊科学, 2009, 21 (6): 873-878.]

[43] Hu Guohua, Tang Zhongwang, Xiao Xiangqun. Trend analysis of water quality of Sanmenxia Reservoir of the yellow river. Geography and Geo-Information Science, 2004, 20(3): 86-88(in Chinese with English abstract). [ 胡国华, 唐忠旺, 肖 翔群. 季节性 Kendall 检验及其在三门峡水库水质趋势分析中的应用. 地理与地理信息科学, 2004, 20(3): 86-88.]

[44] Wang Xiaoyan, Guo Fang, Cai Xinguang et al. Non-point source pollution loading of Miyun Reservoir, Beijing. Urban Environment \& Urban Ecology, 2003, 16(1) : 31-33( in Chinese with English abstract). [王晓燕, 郭芳, 蔡新广等. 密云 水库潮白河流域非点源污染负荷. 城市环境与城市生态, 2003, 16(1) : 31-33.]

[45] Bao Quansheng, Cao Lijun, Wang Huadong. Assessment research of non-point source pollution loading of Miyun Reservoir. Water Resources Protection, 1997, (1) : 8-11 (in Chinese with English abstract). [鲍全盛, 曹利军, 王华东. 密云水库 非点源污染负荷评价研究. 水资源保护, 1997, (1) : 8-11.] 